\title{
Therapeutic strategies for acute intermittent porphyria
}

\author{
Lanlan Zhao ${ }^{1}$, Xinyang Wang ${ }^{1}$, Xiaoning Zhang ${ }^{1}$, Xiantao Liu ${ }^{1}$, Ningzhen Ma ${ }^{1}$, Yiran Zhang ${ }^{2}$, \\ Songyun Zhang ${ }^{1, *}$
}

${ }^{1}$ Department of Endocrinology, The second Hospital of Hebei Medical University, Shijiazhuang, Hebei, China;

${ }^{2}$ School of First Clinical Medical College, Southern Medical University, Guangzhou, Guangdong, China.

SUMMARY Acute intermittent porphyria (AIP) is an autosomal dominant disease caused by mutations in porphobilinogen deaminase (PBGD), the third enzyme of the heme synthesis pathway. Symptoms of AIP usually manifest as intermittent acute attacks with occasional neuropsychiatric crises. The management of AIP includes treatment of acute attacks, prevention of attacks, long-term monitoring and treatment of chronic complications. Intravenous injection of heme is the most effective method of treating acute attacks. Carbohydrate loading is used when heme is unavailable or in the event of mild attacks. Symptomatic treatment is also needed during attacks. Prevention of attacks includes eliminating precipitating factors, heme prophylaxis and liver transplantation. New treatment options include givosiran (siRNA) to down-regulate ALA synthase-1 (ALAS1) and the messenger RNA of PBGD (PBGD mRNA) delivered to the liver cells of patients with AIP. Long-term monitoring of chronic complications includes regular liver-kidney function and hepatocellular carcinoma (HCC) screening.

Keywords acute intermittent porphyria, heme, carbohydrate loading, givosiran (siRNA), mRNA therapy

\section{Introduction}

Acute intermittent porphyria (AIP, MiM 176000) is an inherited autosomal dominant disorder characterized by hepatic deficiency of hydroxymethylbilane synthase (HMBS,HGNC 4982)/porphobilinogen deaminase (PBGD, EC 4.3.1.8), the third enzyme of the heme synthesis pathway (1-3). Regulated by heme stores, ALA synthase-1 (ALAS1) is the first enzyme of the hepatic heme synthesis pathway, and is also a rate-limiting enzyme. In patients with AIP, increased heme demand will lead to the up-regulation of ALAS1 and increase the production and accumulation of aminolevulinic acid (ALA) and porphobilinogen (PBG) $(1,2)$.

Clinical symptoms are related to the accumulation of high levels of porphyrin precursors (4-6). Symptoms of AIP usually manifest as intermittent acute attacks. The most common symptoms during attacks are abdominal pain accompanied by nausea, vomiting, constipation, hypertension and tachycardia (1-3,7). Some patients develop severe neurological complications, including peripheral neuropathy and central nervous system (CNS) involvement, such as acute encephalopathy, convulsions, anxiety, insomnia, depression, seizures and paralysis. After many years of repeated attacks, symptoms may become chronic $(8,9)$.
The management of AIP includes treatment of acute attacks, prevention of attacks, long-term monitoring and treatment for complications (10). The current work summarizes existing and recently developed AIP treatments for those three purposes.

\section{Treatment of acute attacks}

\subsection{Specific therapy}

Pathophysiologically, the aim of treating acute attacks is to suppress hepatic ALAS1 activity. The current treatments for acute attacks involve heme replacement and carbohydrate loading.

\subsubsection{Heme}

Intravenous heme is the most effective therapy; it provides exogenous heme and down-regulates ALAS1 transcription. This, in turn, results in a rapid reduction in the overproduction of ALA and PBG. Heme is isolated and purified from human red cell concentrates, and it has been used for more than 30 years $(4,12)$. Currently, two forms of heme for human use are available: Normosang ${ }^{\circledR}$ heme arginate in Europe and South Africa and Panhematin ${ }^{\circledR}$ heme (Recordati Rare Diseases) in the 
US. Both must be freshly prepared and delivered over $30 \mathrm{~min}$. Heme should be reconstituted in human albumin because of its instability in aqueous solution. Due to the possibility of painful phlebitis as a result of intravenous injection of heme into a peripheral vein, heme should be given via central intravenous. A standard heme regimen is $3-4 \mathrm{mg} / \mathrm{kg} /$ day for 4 days; additional courses may be required if symptoms continue to worsen (13). Due to rapid clinical improvement (often within 1-2 days) once an acute attack occurs, heme should be used as soon as possible, and especially when there are convulsions, hyponatremia, neuropathy or psychosis. Intravenous heme is efficacious even in the late stage of progressing motor neuropathy (14).

Although heme therapy is well tolerated in most cases, repeated treatment increases the risk of hepatic fibrosis and liver iron overload (a heme arginate dose of $250 \mathrm{mg}$ contains $22.7 \mathrm{mg}$ of iron) (15). A point worth mentioning is that experience shows that heme can be used safely during pregnancy (16).

\subsubsection{Carbohydrate loading}

Adequate caloric support (carbohydrates and proteins) is essential to the treatment of AIP (17). Carbohydrate loading was considered to be a standard treatment for acute attacks before the appearance of heme, but it does not alleviate symptoms as quickly as heme. Glucose inhibits ALAS1 by affecting peroxisome proliferatoractivated receptor gamma coactivator1-alpha (PGC1- $\alpha$ ) (the "glucose effect") (18-20).

According to guidelines for the treatment of an acute attack in the US and South Africa, glucose is limited to the treatment of mild attacks (mild pain, no vomiting, no paresis, no seizures, or no hyponatremia) or when heme is not available locally (21). The latter is a challenge in lower-to-middle-income countries (22).

Mild attacks should initially be treated with oral glucose, but patients who are not tolerating oral glucose can be given glucose intravenously (300-500 g/day, preferably $10 \%$ dextrose in $0.45 \%$ saline) as a preferred source of energy $(16,23)$, in order to down-regulate the activity of ALAS1 and prevent fasting (24). Moreover, the combination of glucose with insulin can be more effective because insulin can also hamper ALA synthesis induced by PGC1- $\alpha$ (25). However, hyponatremia worsens with hemodilution caused by large amounts of $10 \%$ glucose. At the same time, the blood sugar level should be monitored regularly to avoid the osmotic effects of glucose (hyperglycemia or hypoglycemia causes additional neurological complications). After emergency intravenous glucose, oral nutrition with carbohydrates should be initiated as soon as possible. Of course, intravenous glucose does not prevent recurrent attacks or long-term consequences (26).

\subsection{Symptomatic treatment}

\subsubsection{Digestive system}

\subsubsection{Abdominal pain management}

Pain stress contributes to neuroendocrine reactions that activate ALAS1 and exacerbate symptoms, so pain management in patients with AIP is crucial and remains a challenge.

Generally, abdominal pain is severe (visual analog scale $(\mathrm{VAS})>7 \mathrm{~cm}$, scale from 0 to $10 \mathrm{~cm})(27)$. Acetaminophen and non-steroidal anti-inflammatory medicines are first-line agents in mild cases (21), but parenteral narcotic analgesics (fast-acting opioid analgesics) are universally used to treat incapacitating pain associated with acute attacks (28). Morphine and buprenorphine are the safest of those medications. An experimental study indicated that fentanyl, tramadol, nalbuphine, oxycodone, and hydrocodone resulted in different degrees of porphyrin accumulation (29). Addiction to medication warrants attention, although few cases of opioid dependence in patients with AIP have been reported (30). In addition, neurolysis of the celiac ganglion with absolute alcohol has been performed as an analgesic strategy in patients with refractory neurovisceral pain, subsequent pain control, and opioid medication withdrawal $(31,32)$. Thus, appropriate therapies (intravenous glucose, heme, and safe analgesics) are administered without delay, and alleviation of pain should result within 3 to 5 days.

\subsubsection{Management of other symptoms}

Phenothiazines, such as chlorpromazine and promethazine, play an important role in managing nausea and vomiting (33). Moreover, studies have indicated their usefulness in managing anxiety, restlessness, pain, and reducing the requirement for opioid analgesics. Of course, ondansetron is also a good choice for treating nausea and vomiting while metoclopramide can trigger an acute attack.

Intestinal obstruction in patients with AIP is considered to be a dynamic obstruction, and constipation is a possible cause of patients' abdominal pain. The treatment strategies for constipation and an intestinal obstruction include eliminating risk factors, giving adequate caloric support, and symptomatic treatment. Most patients improve after discharge. Symptomatic treatment can be given with lactulose (22) or repeated enemas (34).

\subsubsection{Cardiovascular system}

Sympathetic hyperactivity results in tachycardia and systemic arterial hypertension during acute attacks (29). Beta blockers, angiotensin-converting enzyme inhibitors, and calcium channel blockers (diltiazem is preferred over nifedipine) are preferred agents, but 
patients need to be monitored for hypotension and bradycardia (35).

\subsubsection{Nervous system}

Involvement of the CNS manifests as a combination of seizures, syndrome of inappropriate antidiuretic hormone (SIADH), posterior reversible encephalopathy syndrome (PRES), or psychiatric symptoms (agitation, hallucinations, anxiety, and depressive behaviors) $(36,37)$. Overproduction of ALA via neurotoxicity, oxidative damage, modification of glutamatergic release, and increased metabolites of the kynurenine pathway initiates dysfunction of the CNS as mentioned above (38-41). Moreover, the accumulation of ALA is assumed to impair normal $\gamma$-aminobutyric acid (GABA) function, leading to seizures and psychiatric symptoms (42-45). Hypothalamic impairment due to the neurotoxicity of ALA might cause SIADH, which is most often characterized by hyponatremia $(37,44)$. Seizures can occur in the event of ALA neurotoxicity, decreased GABA activity, hyponatremia, hypertension, or PRES $(36,44)$. ALA neurotoxicity and hyponatremia may cause psychiatric symptoms in patients with AIP.

\subsubsection{CNS}

\subsection{Treatment of seizures}

Treatment of seizures is difficult because several commonly used medications are highly risky. Gabapentin, vigabatrin, levetiracetam, and probably bromides or magnesium sulfate can be given safely $(46,47)$. Benzodiazepines including diazepam are relatively safe (48). The safety of valproate and clonazepam is a subject of debate (49). Status epilepticus seizures require sedation with propofol. Intravenous infusion of magnesium sulphate can effectively treat adrenergic symptoms $(45,50,51)$.

Bromides have been successfully used in an attempt to avoid other enzyme-inducing antiepileptic drugs, but they frequently have adverse effects on the skin, gastroenteric, renal systems, and CNS (52). Taylor reported that intravenous magnesium can be used to safely treat seizures in AIP (53). Tatum and Zachariah described successful seizure control with gabapentin in two patients with AIP without exacerbating acute attacks (54). Zadra et al. reported a female patient who had both partial and generalized seizures with AIP and who remained seizure-free and attack-free on gabapentin alone (47). Another report described a patient with hereditary coproporphyria treated with levetiracetam, and that medication did not exacerbate porphyria (55). Zaatreh described a patient with AIP and status epilepticus who was successfully treated with a combination of intravenous magnesium and oral levetiracetam and who was thereafter maintained on oral gabapentin and levetiracetam without any adverse reactions (56). A case involving a 12-year-old boy with AIP and status epilepticus was resolved with intravenous propofol (in addition to the continuation of gabapentin and levetiracetam in the event of episodes of status epilepticus) (57). The management of seizures can be a potential source of iatrogenicity when using carbamazepine, phenytoin, or barbiturates; all can induce acute attacks of porphyria $(54,58,59)$.

Careful correction of hyponatremia and hypertension is necessary, particularly when those conditions are associated with seizures (48). Patients with neurological complications (convulsions, progressive neuropathy, respiratory insufficiency, and encephalopathy) must be cared for in a High Dependency or an Intensive Care Unit (33).

\subsection{Treatment of SIADH}

Hyponatremia is a common symptom of SIADH in patients with AIP. The correction of hyponatremia should be performed according to hyponatremia guidelines developed by professional organizations (6063 ). The strategy should be guided by the symptoms and not just by a reduction in serum $\left[\mathrm{Na}^{+}\right](64)$.

First, SIADH is associated with euvolemic hyponatremia, and fluid restriction $(1 \mathrm{~L} /$ day $)$ is the best option (65). However, carbohydrate loading is the only specific therapy in areas where heme is not available. During carbohydrate loading, fluid restriction is not practical. Moreover, fluid restriction may be poorly tolerated because of increased thirst, resulting in poor compliance $(66,67)$.

Second, patients with severe hyponatremia (serum $\left[\mathrm{Na}^{+}\right]<125 \mathrm{mmol} / \mathrm{L}$ ) should be intravenously infused with a $3 \%$ saline solution as a bolus of $100-150 \mathrm{~mL}$ over 10-20 min; this should be repeated 2-3 times or until the goal of a $5-\mathrm{mEq} / \mathrm{L}$ increase in serum $\left[\mathrm{Na}^{+}\right]$is met (65). For patients with moderate hyponatremia (serum $\left[\mathrm{Na}^{+}\right]$ between $125-129 \mathrm{mmol} / \mathrm{L}$ ), a 3\% hypertonic saline may be administered as a continuous infusion. A formula can be used to calculate the rate of infusion (68). An initial 4-6 $\mathrm{mEq} / \mathrm{L}$ increase is considered sufficient to reduce the risk of brain herniation and neurological damage from cerebral ischemia. The risk of osmotic demyelination syndrome (ODS) increases with chronic hyponatremia. Therefore, a limit of $10-12 \mathrm{mEq} / \mathrm{L}$ in $24 \mathrm{~h}$ or $18 \mathrm{mEq} /$ $\mathrm{L}$ in $48 \mathrm{~h}$ seems to be appropriate for patients without risk factors for ODS. A correction $>8 \mathrm{mEq} / \mathrm{L}$ in $24 \mathrm{~h}$ is sufficient for high-risk patients (62).

Third, loop diuretics that increase free water excretion rates have proven effective in the treatment of SIADH. A combination of low-dose loop diuretics and oral sodium chloride is only recommended in European guidelines $(60,63)$.

Finally, vaptans, and tolvaptan in particular, are selective competitive vasopressin receptor-2 antagonists 
that have been used in recent years (69). The usual starting dose is $15 \mathrm{mg}$ /day. However, lower doses (e.g. $7.5 \mathrm{mg} /$ day) may be effective in clinical practice to guarantee a desired serum $\left[\mathrm{Na}^{+}\right]$increase (64). If the $\left[\mathrm{Na}^{+}\right]$rise is less than $5 \mathrm{mEq} / \mathrm{L}$ in $24 \mathrm{~h}$, the daily dose can be increased up to a maximum of $60 \mathrm{mg}$ (64).

However, overcorrections and adverse reactions, such as hypotension or liver toxicity, are relatively frequent $(70,71)$. Tolvaptan must be discontinued when liver injury is suspected. The use of vaptans differs according to the US recommendations and European guidelines (59-62). The US recommendation suggest using vaptans only in the event of chronic hyponatremia as a second option after fluid restriction.

\subsection{Psychiatric symptoms}

A variety of psychiatric symptoms, such as depression, anxiety, insomnia, and even schizophrenia and hallucinations, may occur during an acute attack (40). Severe agitation, insomnia, and anxiety can be treated with low-dose short-acting benzodiazepines and chlorpromazine (33). Tricyclic antidepressants (TCAs) have the worst security profile among antidepressants. Of all selective serotonin reuptake inhibitors (SSRIs), only fluoxetine is categorized as non-porphyrogenic. A 25-year-old woman with AIP received fluoxetine (20 mg/day) for 9 weeks for depressive symptoms. Fluoxetine seems to be efficacious without causing any adverse reactions (72). Duloxetine is the serotonin norepinephrine reuptake inhibitor (SNRI) with the most favorable profile (40). Hallucinations should be treated with phenothiazine or olanzapine (22). Databases should be consulted to determine the porphyrogenicity of different medications. The Norwegian Porphyria Centre (NAPOS) and American Porphyria Foundation (APF) databases are now available in Porphyria Drug Safety finder (73-75).

\subsubsection{Peripheral nervous system}

Peripheral neuropathy caused by ALA neurotoxicity and heme deficiency is a common neurological manifestation of AIP (60). Patients may present with muscle weakness, paresis, bulbar paralysis, sensory neuropathy (include paresthesia, hypoesthesia, and neuropathic pain), or the like (61-63). The pain score and the severity of muscle weakness should be evaluated daily (22). Bulbar paresis and increasing muscle weakness are signs of an acute attack, and the patient should be transferred to the intensive care unit. Vital capacity, reduced by paralysis of the intercostal muscles, increases the risk of pneumonia and may require early mechanical ventilation (22). It may be necessary for several months if respiratory failure has occurred. Patients with paresis require rehabilitation therapy as soon as possible. Paralysis can usually be reversed with proper management and months of recovery (46).

\section{Prevention of attacks}

\subsection{Eliminating precipitating factors}

The most important preventive measure for AIP is to eliminate all predisposing factors that may cause an acute attack. This includes avoiding unsafe drugs (such as barbiturates, anticonvulsants, some sedatives, antibiotics, antifungals, and hormones), fasting, alcohol use, smoking, infections, and stress and encouraging adequate calorie and carbohydrate intake $(25,33,44)$. These triggers significantly increase the hepatic heme requirement, and the reduction in hepatic free heme leads to the synthesis of ALAS1. Given that drugs are an important cause of acute attacks of AIP, patients with AIP should be referred to the American Porphyria Foundation (APF), the Norwegian Porphyria Centre (NAPOS), or the Porphyria Drug Safety finder to ensure safe use of medications (28). Extreme dieting, severe caloric restriction, and starvation should be avoided (76). Patients should be advised to maintain a balanced diet with a slightly higher carbohydrate content (60$70 \%$ of total calories). There is little evidence that extra carbohydrates in the diet help further prevent attacks, and trying to increase carbohydrate intake may only lead to unwanted weight gain. Obese patients should lose weight gradually while they are clinically stable (10). In addition, patients should give up smoking and limit alcohol. Generally, no more than two drinks a day for men and no more than one for women are recommended (10).

Studies have reported that $10-30 \%$ of cyclical AIP episodes occur in the luteal phase of the menstrual cycle $(77,78)$. Probably the main factor provoking a crisis is the ovarian hormone progesterone (79-80). Progesterone is a porphyrin inductor and an effective inducer of ALAS1 $(78,81)$. Therefore, women with recurrent premenstrual attacks of AIP can be given GnRH analogues (leuprolide or histrelin) to prevent ovulation and alleviate symptoms (16). GnRH treatment is initiated during the first 1-3 days of a menstrual cycle to reduce the risk of an AIP attack precipitated by transient ovarian stimulation (15). Possible adverse reactions include depression, hot flushes, reduced libido, osteoporosis, and other menopausal symptoms (33). Women with frequent attacks that appear to be associated with their cycle can tentatively receive a $\mathrm{GnRH}$ analogue for 3 months, and it can be discontinued if ineffective (15). Receiving the GnRH analogue continuously for more than 6 months carries an irreversible risk of bone loss. If, therefore, such treatment continues, a low dose of estradiol (preferably via the percutaneous route) or bisphosphonate may be added to prevent bone loss and other adverse reactions, or the treatment may be switched to a low-dose oral 
contraceptive (10). Bone density should be assessed annually to ensure there is no ongoing bone loss. In addition, there is a continuing risk of endometrial dysplasia in the absence of progesterone, so endometrial monitoring by a gynecologist should be performed at least annually (15). The efficacy of GnRH analogues should be reviewed after one year (33).

\subsection{Heme prophylaxis}

Heme prophylaxis may be effective in preventing attacks, and it is particularly appropriate in preventing frequent (four or more episodes per year), noncyclic attacks (15). The prophylactic dose of heme is 3-4 mg/ $\mathrm{kg}$ of body weight, once or twice a week, administered intravenously $(10,81)$. Heme is a short-acting drug. Therefore, prophylactic administration of heme is less likely to be effective if administered less frequently than weekly (81). The main adverse reaction to frequent use is damage to the superficial venous system, which may necessitate the use of a central venous catheter. Iron overload is a major complication, and serum ferritin should be monitored in the event of repeated use (44). If necessary, a phlebotomy should be performed to treat iron overload (15). Serum ferritin may not be a reliable indicator of iron overload in some circumstances, as ferritin levels may rise sharply after hemin infusion (81). Other potential adverse reactions to intravenous heme include transient thrombocytopenia and prolongation of prothrombin time $(82,83)$.

After 6-12 months of repeated prophylactic treatment, the need for continued prophylactic use of heme should be reassessed. A study has reported that stopping treatment and starting again if necessary may be more effective than gradually reducing the dose or the number of doses given (15).

Compared to the treatment of acute attacks, weekly planned prophylactic use of heme significantly reduced the number of hospitalizations and emergency department visits by patients with AIP, thus improving their overall quality of life (84). Another important benefit was an improved doctor-patient relationship, which is crucial to better management of patients with AIP.

\subsection{Liver transplantation}

Correcting genetic defects in PBG deaminase through orthotopic liver Transplantation (OLT) is an alternative to suppressing ALAS activation. This approach has been found to be an effective treatment option that alleviates symptoms and normalizes biomarkers within 3 days of transplantation (44). Indications for OLT include intractable acute attacks not responsive to medical treatment, recurrent acute attacks severely affecting quality of life, and repeated severe lifethreatening acute attacks leading to prolonged ventilation (26,33). In AIP, common complications of OLT include hemorrhage, bile leak, and renal dysfunction (87). Studies have reported an increased risk of hepatic artery thrombosis (HAT) in patients with AIP who undergo OLT. Up to $40 \%$ of patients with AIP after liver transplantation have HAT $(85,86)$. Ten patients with AIP have undergone OLT in the UK and Ireland and have been cured with biochemical and clinical remission. However, HAT occurred in 4 of the 10 patients who received liver transplants for AIP (85). For this reason, routine anticoagulation is administered post-operatively (44). In addition, hemin injection may lead to an iron overload and vascular damage, which may limit the the conduct of OLT (86). Lastly, patients who have hepatic iron overload pre-transplant have worse long-term outcomes following transplantation (87). Moreover, transplantation cannot completely repair the long-standing injury to motor nerves and the CNS (88).

\subsection{Emerging therapy-Givosiran (siRNA-ALAS1)}

\subsubsection{Mechanism}

With advances in small interfering RNA (siRNA) and its targeting technology, siRNA targeting liver ALAS1 expression has become a new treatment for $\operatorname{AIP}(89,90)$. Givosiran (Alnylam Pharmaceuticals, Cambridge, MA, USA), a double-stranded ALAS1 specific siRNA, is linked to a ligand containing three $\mathrm{N}$-acetylgalactosamine (GalNAc) residues that targets and interacts with liver asialoglycoprotein receptor (ASGPR) $(91,92)$. Within the hepatocyte, RNA is cleaved by cellular enzymes into fragments of approximately $20 \mathrm{bp}$ and then separated into single strands, which bind to and silence ALAS1 mRNA, therefore inhibiting the translation and expression of the ALAS1 protein $(1,91,92)$.

\subsubsection{Trials}

In preclinical studies of rodent and non-human primate models of AIP, use of an siRNA targeting ALAS1 (siRNA-ALAS1) was associated with a rapid reduction in urine and plasma ALA and PBG levels and effective prevention of acute attacks $(93,94)$. In a phase I clinical trial (NCT02452372) in adults with AIP, a single $2.5-\mathrm{mg} / \mathrm{kg}$ dose of givosiran similarly resulted in a maximum average reduction in the urinary ALA, PBG, and $A L A S 1$ mRNA levels by $86 \%, 91 \%$, and $96 \%$, respectively $(91,95)$. In patients with recurrent acute attacks, a once-monthly dose of givosiran $(2.5$ or $5 \mathrm{mg} /$ $\mathrm{kg}$ ) resulted in a maximum reduction of ALAS1 mRNA from baseline levels of $67 \%$ or $74 \%(95,96)$. Urinary ALAS1 mRNA levels were significantly associated with ALA and PBG levels $(P<0.001)(93)$.

In a multinational phase III clinical trial (NCT03338816), 89 patients with AIP were randomly 
assigned to receive subcutaneous givosiran $(2.5 \mathrm{mg} /$ $\mathrm{kg}$ ) monthly or a placebo for 6 months (97). Compared to the placebo group, monthly subcutaneous injection of givosiran $2.5 \mathrm{mg} / \mathrm{kg}$ significantly reduced the composite annualized attack rate (ARR) for AIP attacks (mean composite ARR 3.2 vs. 12.5) (91). The median composite ARR was 10.7 for givosiran and 1.0 for the placebo. During the period of the intervention, the percentage of patients without acute attacks in the treatment group increased threefold compared to the placebo group (50 vs. 17\%) $(91,95)$. In the treatment group, the mean annualized number of days of heme use was markedly lower than that in the placebo group (6.8 vs. 29.7days) (91). The percentage of patients that used any opioids in the treatment group decreased by $20 \%$ compared to the placebo group (67vs. 88\%) (97). The average ALA and PBG levels in the givosiran group were $77 \%$ and $76 \%$, respectively $(86,96,97)$.

\subsubsection{Pharmacokinetics}

Givosiran is absorbed from the subcutaneous (SC) injection site, reaches a peak plasma concentration within 0.5-5 hours, and is then eliminated with a half-life of 4-10 hours (96). Givosiran and its active metabolite AS(N-1) 3'givosiran have equal potency $(91,96,98)$. Givosiran and AS(N-1) 3'givosiran reduce the levels of ALA and PBG in a dose-dependent manner over the 0.35 to $2.5 \mathrm{mg} / \mathrm{kg}$ dose range $(95,96)$. However, increasing the dose to $5.0 \mathrm{mg} / \mathrm{kg}$ did not result in an additional reduction in $\mathrm{PBG}$ at a dose of $2.5 \mathrm{mg} / \mathrm{kg}$ (96). Compared to quarterly administration, monthly administration results in greater and more sustained reductions in ALA and PBG (95).

Preclinical research indicated that siRNA-ALAS1 did not cause hepatic heme deficiency and did not decrease cytochrome P450 2E1 activity $(94,95)$. In a drug-drug interaction study, however, givosiran had a moderate effect on CYP2D6 and CYP1A2, a weaker effect on CYP3A4 and CYP2C19, and no effect on CYP2C9. The simultaneous use of givosiran with CYP1A2 (e.g. caffeine) and CYP2D6 (e.g. opioid) substrates should be avoided since this medicine may increase or prolong their therapeutic effect $(98,91)$.

\subsubsection{Adverse reactions}

In a phase III clinical trial of givosiran, common adverse reactions occurred more frequently in the givosiran group than in the placebo group $(91,97)$. Those reactions were elevated transaminase (15 vs. $2 \%)$, increased serum creatinine (CRE) (15 vs. 4\%), injection site reactions (25 vs. 0\%), nausea (27 vs. 11\%), a rash (17 vs. 4\%), and fatigue (10 vs. 4\%). Sardh et al. reported that one patient had a serious adverse event (spontaneous abortion) after receiving givosiran at a dose of $1.0 \mathrm{mg} /$ $\mathrm{kg}$ (95). In placebo-controlled and open-label studies, one patient $(0.9 \%)$ had an allergic reaction, and another patient $(0.9 \%)$ developed treatment-induced anti-drug antibodies (ADA) during treatment (98). The levels of alanine transaminase (ALT) increased mainly within 3-5 months after administration, and elevated levels in most patients return to normal after givosiran was continued $(91,98)$. In a phase III clinical trial, one patient $(0.9 \%)$ in the givosiran group discontinued treatment due to elevated ALT 9.9 times the upper limit of normal (ULN). One patient with an elevated ALT of 5.4 times the ULN temporarily discontinued treatment and resumed at a lower dose $(1.25 \mathrm{mg} / \mathrm{kg})$, without elevated ALT recurring (97). Decreased liver detoxification capacity maybe a potential complication of longterm downregulation of ALAS1 $(11,96)$. However, givosiran has not been linked to acute liver impairment with jaundice (99). The increased CRE level and associated decreases in the glomerular filtration rate (eGFR), which occurred early during the 6-month period, are considered mostly transient and reversible (97). For chronic diseases, the 6-month follow-up period is relatively short, and a longer follow-up period is needed to evaluate the safety of treatment (11). There are limited data on the use of givosiran by pregnant women. Studies in animals have found that administration of givosiran during organogenesis resulted in adverse developmental outcomes $(97,98)$. Human heme oxygenase 1(HMOX1) is an enzyme that plays a key role in placental biology, heme is a substrate of HMOX1, and the placenta expresses givosiran-targeted ASGPR (100). To minimize the risk of pregnancy, all programs require women to use birth control when receiving givosiran (97). Injection-site reactions to givosiran is similar to those of other RNA interference drugs (e.g. patisiran), indicating that this may be related to this type of drug (11).

\subsubsection{Medication instructions}

Givosiran is approved by the US Food and Drug Administration (FDA) and European Medicines Agency (EMA) as a drug for acute hepatic porphyria (AHP) in adults and adolescents 12 years of age and older $(98,101)$. The dose for patients $\geq 12$ years to $<18$ years is the same as for adults $(91,98)$. The approved dose for an SC injection of givosiran is $2.5 \mathrm{mg} / \mathrm{kg}$ once a month; if a dose is missed, it should be given as soon as possible. The dose does not need to be adjusted for patients with mild liver impairment, bilirubin $\leq 1 \times$ ULN and aspartate aminotransferase $($ AST) $>1 \times$ ULN, or bilirubin $>1 \times$ ULN to $1.5 \times$ ULN. Discontinuing the drug and reusing at dose of $1.25 \mathrm{mg} / \mathrm{kg}$ once monthly should be considered for patients with clinically relevant elevated ALT (98). No studies have been conducted in patients with end-stage renal disease and moderate or severe liver impairment $(91,98)$. (features and applications of givosiran are shown in Table 1) 
Table 1. Features and applications of givosiran

\begin{tabular}{|c|c|}
\hline Alternative names & Givlaari $^{\mathrm{TM}}$ \\
\hline Mechanism of action & small interfering RNA (siRNA); targeting ALAS1 mRNA \\
\hline Indications & AHP in adults and adolescents 12 years and older \\
\hline Posology and method of administration & $2.5 \mathrm{mg} / \mathrm{kg}$, once monthly, subcutaneous injection \\
\hline Interaction with other medicines & $\begin{array}{l}\text { CYP1A2 Theophylline; caffeine } \\
\text { CYP2D6 Pain management (opioid, NSAIDs, and triptan) } \\
\text { Antidepressants (TCAs, SSRIs, and SNRIs) } \\
\text { Antipsychotics }\end{array}$ \\
\hline Adverse reactions & Hypersensitivity, nausea, rash, elevated transaminase, fatigue, decreased eGFR, injection site reactions \\
\hline Dose modification for adverse reactions & $1.25 \mathrm{mg} / \mathrm{kg}$ dose per month \\
\hline Fertility, pregnancy, and lactation & Uncertain \\
\hline
\end{tabular}

\subsection{Potential treatment}

New therapeutic advances indicate that AIP can be addressed etiologically by correcting the deficiency in PBGD. The first approach involves increasing the expression of the deficient protein via recombinant adeno-associated virus (rAAV)-mediated transfer of human $P B G D(h P B G D)$ cDNA. In the second method, $h P B G D$ mRNA is packaged into lipid nanoparticles (LNP) and taken up by hepatocytes (102).

\subsection{1. $P B G D$ cDNA}

Due to their poor transfection efficiency, AIP gene therapies with a non-viral vector and first-generation adenovirus vector were unsuccessful (103-104). Now, rAAV vectors have good biological safety and can maintain a high level of liver transgene expression for a long time (105). The introduction of the $P B G D$ gene into mice with AIP via non-viral vectors does not produce sufficient levels of PBGD (103). Annika et al. successfully transfected adenovirus-mediated $P B G D$ cDNA into PBGD-deficient mice $(104,106)$. This led to increased PBGD expression in the liver and eliminated the accumulation of ALA and PBG in mice with AIP induced by phenobarbital. However, the first-generation adenovirus-mediated transgene is not suitable for clinical use because of transient expression and host cell immune response (104).

Makiko et al. injected the rAAV8 serotype vector (rAAV2/8- $h P B G D$ ) encoding the mouse $h P B G D$ gene into the peritoneum of mice with AIP, resulting in an increase in liver PBGD activity. During acute attacks, it prevented an increase ALA and PBG over 36 weeks (105). rAAV8-mediated PBGD activity may increase the biosynthesis of heme and then down-regulate the expression of liver ALAS1. Importantly, rAAV2/8$h P B G D$ treatment improved neuromotor function in mice with AIP $(106,107)$. Adding specific enhancer factors to the promoter of the AIP gene vector can enhance gene expression in mice with AIP $(108,109)$.

In 2009, this gene therapy vector was utilized as an orphan drug for the treatment of AIP (110). In an initial human phase I clinical trial (NCT02082860), therapy with the rAAV5 vector encoding $h P B G D$ (rAAV2/5$h P B G D)$ proved safe in patients with AIP $(105,111)$. No serious adverse events related to treatment were observed after 8 patients were intravenously injected. Although ALA and PBG levels remain unchanged, the number of hospitalizations and frequency of heme treatment tend to decrease. All patients developed neutralizing antibodies against rAAV5. An important safety issue is the potential genotoxicity of the vector (111). Nault et al. reported the presence of integrated wild-type (wt) AAV genomes in HCC samples from 11 of 193 patients (112). However, the AAV vectors detected in liver biopsies from 6 patients with AIP after 1 year of treatment did not involve the carcinogenic regions reported in patients with $\operatorname{HCC}(105,111)$.

Liver-directed gene therapy may be effective in correcting AIP. However, this technology has many unresolved problems. First, there are no biochemical indicators of the effectiveness of gene therapy $(102,105)$. Second, repeated administration is required. However, initial exposure to the viral vector will lead to the development of neutralizing antibodies $(17,102)$. Therefore, rAAV-hPBGD gene therapy requires a balance between sufficient transgene expression and destructive immune responses, and this may be affected by the serotype of the rAAV vector. Finally, individual differences in transfection efficiency lead to inherent variability in levels of PBGD protein expression $(17,105)$.

\subsection{2. $P B G D$ mRNA}

Compared to rAAV-hPBGD gene therapy, $h P B G D$ mRNA packed into LNP may be a cheaper and less immunogenic strategy. In addition, mRNA does not require nuclear localization, so it has minimal risk 
of causing an insertion mutation (17). LNP protects mRNA from nuclease-mediated degradation (113). It also shields mRNA from the immune system (114). LNP interacts with apolipoprotein E (ApoE) and lowdensity lipoprotein (LDL) receptors, which mediate the internalization of LNP into hepatocytes (113). $h P B G D$ mRNA can produce PBGD protein in the liver of patients with AIP through the cell's endogenous translation mechanism (113-115).

In animal models of AIP, Jiang et al. gave mice a single intravenous injection of LNP encoding $h P B G D$ mRNA at different doses $(0.2$ or $0.5 \mathrm{mg} / \mathrm{kg})$. More than $90 \%$ of hepatocytes expressed high levels of hPBGD protein $2 \mathrm{~h}$ after administration. On day 10 postinjection, this protein is still detectable, indicating that it can remain in the liver for a long time (116). During an acute attack of AIP induced with phenobarbital, a single injection of $h P B G D$ mRNA $(0.2$ or $0.5 \mathrm{mg} / \mathrm{kg})$ can rapidly normalize ALA and PBG levels. Intravenous injection of mRNA can prevent acute attacks of AIP. There is a link between the dose and efficiency of a single administration (17). Mice with AIP that received $h P B G D$ mRNA $(0.05$ or $0.1 \mathrm{mg} / \mathrm{kg})$ had partial protection against $P B G$ accumulation and pain. In contrast, doses of $h P B G D$ mRNA $(0.2$ or $0.5 \mathrm{mg} / \mathrm{kg}$ ) provided full protection against $\mathrm{PBG}$ accumulation and pain $(102,117)$.

Surprisingly, intravenous injection of $h P B G D$ mRNA can protect against the significant up-regulation of hepatic ALAS1 during recurrent acute attacks of AIP in mice (117). $h P B G D$ mRNA can normalize the storage of heme in hepatocytes. $h P B G D$ mRNA can not only deal with abnormal biochemical indicators but also protect against pain and movement disorders. It also normalizes high blood pressure during acute attacks $(17,117)$. Repeated intravenous injection of $h P B G D$ mRNA was well tolerated by mice and nonhuman primates. No adverse events occurred during administration or follow-up (117). After single and repeated intravenous injections of $h P B G D$ mRNA $(0.5$ $\mathrm{mg} / \mathrm{kg}$ ), PBGD protein activity increased by $80 \%$ while liver function was still within the normal range. In addition, there were no significant changes in antibodies against the hPBGD protein (ADA) $(113,117)$.

In general, intravenous injection of $h P B G D$ mRNA can induce the expression of PBGD protein in nonhuman hepatocytes and rapidly normalize the excretion of porphyrin precursors during acute attacks (117). Repeated administration has sustained efficacy without causing adverse events. Moreover, $h P B G D$ mRNA protects against hypertension, pain, and movement disorders. Clinical trials need to be conducted to verify the safety and feasibility of this promising treatment (102).

\section{Long-term monitoring and treatment of chronic complications}

Chronic complications of AIP include systemic arterial hypertension, renal impairment, liver impairment, HCC, chronic pain, a few psychiatric symptoms, and peripheral neuropathy. AIP causes a high incidence of systemic arterial hypertension, which is a key cause of renal impairment, so timely antihypertensive treatment should be provided. Annual examination of creatinine and eGFR are also recommended for all patients. In addition, patients with AIP should refrain from using nephrotoxic drugs and drink more water (16). The angiotensin-converting enzyme inhibitor losartan may delay the development of renal impairment $(10,102)$. If the patient has already developed renal impairment, blood purification or kidney transplantation is often helpful. For patients with AIP and kidney failure, renal transplantation or combined liver-kidney transplantation can have a good curative effect (16, 102). Liver impairment is common in patients with AIP. The incidence of HCC in symptomatic patients with AIP over 50 years of age is about $3 \%$, which is about 80 times higher than that in individuals without AIP $(1,10,118)$. Liver enzymes and liver function should be regularly checked in patients to determine if liver impairment has occurred $(16,46)$. Alpha-fetoprotein (AFP) should be checked and ultrasound should be performed annually on patients over the age of 50 years to facilitate the early discovery of $\operatorname{HCC}(10,16,46)$. Screening for $\mathrm{HCC}$ is even more important if $\mathrm{PBG}$ and ALA levels continue to rise (10). Treatment with ursodeoxycholic acid and cholestyramine is a potential option for patients with liver impairment. Elimination of redundant protoporphyrin via plasma exchange can also delay the progression of liver impairment (119). OLT is the most thorough treatment for liver failure and HCC. Pain due to porphyria can be chronic and should be prevented from becoming acute pain. Medications such as gabapentin and amitriptyline can alleviate chronic pain (28). Patients with AIP may also experience a variety of psychiatric symptoms, such as depression and anxiety. In addition, individuals with AIP are four times more likely to suffer from bipolar disorder or schizophrenia than those without AIP (120). Peripheral neuropathy can also become chronic and may present as multiple mononeuritis or myasthenic syndrome (28). Therefore, patients with AIP should be monitored for psychiatric symptoms and peripheral neuropathy, and rehabilitation therapy should be provided.

\section{Conclusion}

As a rare disease, AIP can pose a challenge in terms of treatment and management. Heme and glucose are specific treatments for acute attacks. In addition, symptomatic treatment is necessary. Educating patients to eliminate precipitating factors is the key to preventing attacks. Heme prophylaxis can effectively control recurrence. The emergence of givosiran represents 
Table 2. Symptomatic therapy and safe medicines for acute attacks

\begin{tabular}{|c|c|}
\hline Symptoms & Medication/therapy \\
\hline \multicolumn{2}{|l|}{ Autonomic neuropathy } \\
\hline \multirow[t]{3}{*}{ Abdominal pain } & Acetaminophen \\
\hline & Non-steroidal anti-inflammatory drugs \\
\hline & Morphine and buprenorphine \\
\hline Nausea & Ondansetron \\
\hline \multirow[t]{2}{*}{ Vomiting } & Chlorpromazine \\
\hline & Promethazine \\
\hline Intestinal obstruction & Glycogen and symptomatic treatment \\
\hline Constipation & Lactulose \\
\hline Urinary retention & Urethral catheter \\
\hline Tachycardia & Beta blockers \\
\hline \multirow[t]{3}{*}{ Hypertension } & Angiotensin-converting enzyme inhibitors \\
\hline & Beta blockers \\
\hline & Calcium channel blockers \\
\hline \multicolumn{2}{|l|}{ Central neuropathy } \\
\hline \multirow[t]{6}{*}{ Seizures } & Correction of hyponatremia and \\
\hline & hypertension \\
\hline & Gabapentin \\
\hline & Levetiracetam \\
\hline & Diazepam \\
\hline & Propofol \\
\hline \multirow[t]{4}{*}{ SIADH } & Fluid restriction \\
\hline & Infusion of saline solution \\
\hline & Vaptans \\
\hline & Loop diuretics \\
\hline \multicolumn{2}{|l|}{ Peripheral neuropathy } \\
\hline Muscle weakness & Rehabilitation \\
\hline $\begin{array}{l}\text { Respiratory muscle } \\
\text { paresis }\end{array}$ & Mechanical ventilation \\
\hline \multicolumn{2}{|l|}{ Psychosis } \\
\hline \multirow{2}{*}{$\begin{array}{l}\text { Insomnia and/or } \\
\text { anxiety }\end{array}$} & Benzodiazepines including zopiclone and \\
\hline & Chlorpromazine \\
\hline \multirow[t]{2}{*}{ Depression } & Fluoxetine \\
\hline & Duloxetine \\
\hline \multirow[t]{2}{*}{ Hallucinations } & Phenothiazines \\
\hline & Olanzapine \\
\hline
\end{tabular}

great progress in treating AIP based on its etiology, and $h P B G D$ mRNA is a promising treatment. Liver transplantation is the last resort for patients with AIP. Generally, patients with AIP need long-term monitoring. Symptomatic therapies and safe medicines to treat acute AIP attacks are summarized in Table 2.

\section{References}

1. Bissell DM, Anderson KE, Bonkovsky HL. Porphyria. N Engl J Med. 2017; 377:862-872.

2. Puy H, Gouya L, Deybach JC. Porphyrias. Lancet. 2010; 375:924-937.

3. Harper P, Sardh E. Management of acute intermittent porphyria. Expert Opinion on Orphan Drugs. 2014; 2:349-
368.

4. Bonkovsky HL, Guo JT, Hou W, Li T, Thapar M. Porphyrin and heme metabolism and the porphyrias. Compr Physiol. 2013; 3:365-401.

5. Meyer U, Schuurmans M, Lindberg R. Acute porphyrias: Pathogenesis of neurological manifestations. Semin Liver Dis. 1998; 18:43-52.

6. Kauppinen R, Mustajoki P. Prognosis of acute porphyria: occurrence of acute attacks, precipitating factors, and associated diseases. Medicine (Baltimore). 1992; 71:1-13.

7. Kauppinen R. Porphyrias. Lancet. 2005; 365:241-252.

8. Bonkovsky HL, Maddukuri VC, Yazici C, Anderson KE, Bissell DM, Bloomer JR, Phil lips JD, Naik H, Peter I, Baillargeon G. Acute porphyrias in the USA: Features of 108 subjects from Porphyrias Consortium. Am J Med 2014; 127:1233-1241.

9. Bonkowsky HL, Schady W. Neurologic manifestations of acute porphyria. Semin Liver Dis. 1982; 2:108-124.

10. Anderson KE. Acute hepatic porphyrias: Current diagnosis \& management. Mol Genet Metab. 2019; 128:219-227.

11. Gonzalez AG. Givosiran - Running RNA interference to fight porphyria attacks. N En gl Med.2020; 382:23662367.

12. Bonkowsky HL, Tschudy DP, Collins A, Doherty J, Bossenmaier I, Cardinal R, Watson CJ. Repression of the overproduction of porphyrin precursors in acute intermittent porphyria by intravenous infusions of hematin. Proc Natl Acad Sci U S A. 1971; 68:2725-2729.

13. Bissell DM. Treatment of acute hepatic porphyria with hematin. J Hepatol. 1988; 6:1-7.

14. Mustajoki P, Nordmann Y. Early administration of heme arginate for acute porphyric attacks. Arch Intern Med. 1993; 153:2004-2008.

15. Bonkowsky HL, Tschudy DP, Collins A, Doherty J, Bossenmaier I, Cardinal R, Watson CJ. Acute hepatic porphyrias: Recommendations for evaluation and longterm management. Hepatology. 2017; 66:1314-1322.

16. Wang B, Rudnick S, Cengia B, Bonkovsky HL. Acute hepatic porphyrias: Review and recent progress. Hepatol Commun. 2018; 3:193-206.

17. Fontanellas A, Ávila MA, Berraondo P. Emerging therapies for acute intermittent porphyria. Expert Rev Mol Med. 2016; 18:e17.

18. Handschin C, Lin J, Rhee J, Peyer AK, Chin S, Wu PH, Meyer UA, Spiegelman BM. Nutritional regulation of hepatic heme biosynthesis and porphyria through PGC1alpha. Cell. 2005; 122:505-515.

19. Welland FH, Hellman ES, Gaddis EM, Collins G, Hunter GW Jr, Tschudy DP. Factors affecting the excretion of porphyrin precursors by patients with acute intermittent porphyria I. The effect of diet. Metabolism: Clinical and Experimental, 1964; 13:232-250.

20. Felsher BF, Redeker AG. Acute intermittent porphyria: Effect of diet and griseofulvin. Medicine (Baltimore). 1967; 46:217-223.

21. Pischik E, Kauppinen R. An update of clinical management of acute intermittent porphyria. Appl Clin Genet. 2015; 8:201-214.

22. Fatima SA, Jurair H, Abbas Q, Rehman AJ. Paediatric porphyria and human hemin: A treatment challenge in a lower middle income country. BMJ Case Rep. 2020; 13:e232236

23. Tschudy DP, Valsamis M, Magnussen CR. Acute intermittent porphyria: clinical and selected research aspects. Ann Intern Med. 1975; 8 3:851-864. 
24. Tschudy DP, Welland FH, Collins A. The effect of carbohydrate feeding on the induction of deltaaminolevulinic acid synthetase. Metabolism. 1964; 13:396-406.

25. Stein PE, Badminton MN, Barth JH, Rees DC, Sarkany $\mathrm{R}$, Stewart MF, Cox TM. Acute intermittent porphyria: Fatal complications of treatment. Clin Med (Lond).2012; 12:293-294.

26. Arora S, Young S, Kodali S, Singal AK. Hepatic porphyria: A narrative review. India J Gastroenterol. 2016; 35:405-418.

27. Jensen MP, Karoly P. Self-report scales and procedures for assessing pain in adults. In: Melzack R, editor. Handbook of Pain Assessment. New York: Guildford Press; 1992: 13-151.

28. Cardenas JL, Guerrero C. Acute intermittent porphyria: General aspects with focus on pain. Curr Med Res Opin. 2018; 34:1309-1315.

29. Lambrecht RW, Gildemeister OS, Williams A, Pepe JA, Tortorelli KD, Bonkovsky HL. Effects of selected antihypertensives and analgesics on hepatic porphyrin accumulation. Biochem Pharmacol. 1999; 58:887-896.

30. Procter EA, McKenzie IP. Opiate dependence in acute intermittent porphyria. Ir J Psychol Med 1994; 11:133134.

31. Tsao YC, Niu DM, Chen JT, Lin CY, Lin YY, Liao KK. Gabapentin reduces neurovisceral pain of porphyria. Acta Neurol Taiwan. 2010; 19:112-115.

32. Ferrari AP, Ardengh JC. Endosonography-guided celiac plexus neurolysis in the treatment of pain secondary to acute intermittent porphyria. Endoscopy. 2002; 34:341342.

33. Stein P, Badminton M, Barth J, Rees D, Stewart MF. British and Irish Porphyria Network. Best practice guidelines on clinical management of acute attacks of porphyria and their complications. Ann Clin Biochem. 2013; 50:217-223.

34. BERLIN R. Excessive constipation with indoluria simulating acute porphyria. Acta Med Scand. 1957; 158:113-116.

35. Khanderia U, Bhattacharya A. Acute intermittent porphyria: Pathophysiology and treatment. Pharmacotherapy. 1984; 4:144-150.

36. Jaramillo-Calle DA, Solano JM, Rabinstein AA, Bonkovsky HL. Porphyria-induced posterior reversible encephalopathy syndrome and central nervous system dysfunction. Mol Genet Metab. 2019; 128:242-253.

37. Zainuddin NM, Sthaneshwar P, Vethakkan SRDB. Acute intermittent porphyria: A rare cause of hyponatraemia. Malays J Pathol. 2019; 41:369-372.

38. Lavandera J, Rodríguez J, Ruspini S, Meiss R, Zuccoli JR, Martínez Mdel C, Gerez E, Batlle A, Buzaleh AM. Pleiotropic effects of 5-aminolevulinic acid in mouse brain. Biochem Cell Biol. 2016; 94:297-305.

39. Satoh Y, Iwadate R, Watanabe Y, Kawai H, Kudo N, Kawashima Y, Mitsumoto A. Manifestation of psychiatric behaviors in a mouse model of griseofulvin-induced hepatic porphyria. J Toxicol Sci. 2008; 33:599-608.

40. Duque-Serrano L, Patarroyo-Rodriguez L, Gotlib D, Molano-Eslava JC. Psychiatric aspects of acute porphyria: A comprehensive review. Curr Psychiatry Rep. 2018; 20:5.

41. Lelli SM, Mazzetti MB, San Martín de Viale LC. Hepatic alteration of tryptophan metabolism in an acute porphyria model its relation with gluconeogenic blockage. Biochem
Pharmacol. 2008;75:704-712.

42. Demasi M, Penatti CA, DeLucia R, Bechara EJ. The prooxidant effect of 5-aminolevu linic acid in the brain tissue of rats: Implications in neuropsychiatric manifestations in porphyrias. Free Radic Biol Med. 1996; 20:291-299.

43. Brennan MJ, Cantrill RC. Delta-aminolaevulinic acid is a potent agonist for GABA auto receptors. Nature. 1979; 280:514-515.

44. Spiritos Z, Salvador S, Mosquera D, Wilder J. Acute intermittent porphyria: Current perspectives and case presentation. Ther Clin Risk Manag. 2019; 15:1443-1451.

45. Tracy JA, Dyck PJ. Porphyria and its neurologic manifestations. Handb Clin Neurol. 2014; 120:839-849.

46. Rigor J, Pinto SA, Martins-Mendes D. Porphyrias: A clinically based approach. Eur J Intern Med. 2019; 67:2429.

47. Zadra M, Grandi R, Erli LC, Mirabile D, Brambilla A. Treatment of seizures in acute intermittent porphyria: Safety and efficacy of gabapentin. Seizure. 1998; 7:415416.

48. Anderson KE, Bloomer JR, Bonkovsky HL, Kushner JP, Pierach CA, Pimstone NR, Desnick RJ. Recommendations for the diagnosis and treatment of the acute porphyrias. Ann Intern Med. 2005; 142:439-450.

49. Dombeck TA, Satonik RC. The porphyrias. Emerg Med Clin North Am. 2005; 23:885-899.

50. Bonkovsky HL, Dixon N, Rudnick S. Pathogenesis and clinical features of the acute hepatic porphyrias (AHPs). Mol Genet Metab. 2019; 128:213-218.

51. Cappellini MD, Brancaleoni V, Graziadei G, Tavazzi D, Di Pierro E. Porphyrias at a glance: Diagnosis and treatment. Intern Emerg Med. 2010; 5 Suppl 1:S73-80.

52. Magnussen CR, Doherty JM, Hess RA, Tschudy DP. Grand mal seizures and acute intermittent porphyria. The problem of differential diagnosis and treatment. Neurology. 1975; 25:121-125.

53. Taylor RL. Magnesium sulfate for AIP seizures. Neurology. 1981; 31:1371-1372.

54. Tatum WO $4^{\text {th }}$, Zachariah SB. Gabapentin treatment of seizures in acute intermittent porphyria. Neurology. 1995; 45:1216-1217

55. Paul F, Meencke HJ. Levetiracetam in focal epilepsy and hepatic porphyria: A case repo rt. Epilepsia. 2004; 45:559560.

56. Zaatreh MM. Levetiracetam in porphyric status epilepticus: A case report. Clin Neuropharmacol. 2005; 28:243-244.

57. Bhatia R, Vibha D, Srivastava MV, Prasad K, Tripathi M, Bhushan Singh M. Use of propofol anesthesia and adjunctive treatment with levetiracetam and gabapentin in managing status epilepticus in a patient of acute intermittent porphyria. Epilepsia. 2008; 49:934-936.

58. Bonkowsky HL, Sinclair PR, Emery S, Sinclair JF. Seizure management in acute hepatic porphyria: Risks of valproate and clonazepam. Neurology. 1980; 30:588592.

59. Larson AW, Wasserstrom WR, Felsher BF, Chih JC. Posttraumatic epilepsy and acute intermittent porphyria: Effects of phenytoin, carbamazepine, and clonazepam. Neurology. 1978; 28:824-828.

60. Spasovski G, Vanholder R, Allolio B, et al. Clinical practice guideline on diagnosis and treatment of hyponatraemia [published correction appears in Nephrol Dial Transplant. 2014 Jun;40(6):924]. Nephrol Dial 
Transplant. 2014; 29 Suppl 2:i1-i39.

61. Spasovski G, Vanholder R, Allolio B, et al. Clinical practice guideline on diagnosis and treatment of hyponatraemia. Eur J Endocrinol. 2014; 170:G1-G47.

62. Verbalis JG, Goldsmith SR, Greenberg A, Korzelius C, Schrier RW, Sterns RH, Thompson CJ. Diagnosis, evaluation, and treatment of hyponatremia: expert panel recommendations. Am J Med. 2013; 126:S1-S42.

63. Mrozek S, Rousset D, Geeraerts T. Pharmacotherapy of sodium disorders in neurocritical care. Curr Opin Crit Care. 2019; 25:132-137.

64. Peri A. Management of hyponatremia: Causes, clinical aspects, differential diagnosis and treatment. Expert Rev Endocrinol Metab. 2019; 14:13-21.

65. Hoorn EJ, Zietse R. Diagnosis and treatment of hyponatremia: Compilation of the guidelines. J Am Soc Nephrol. 2017; 28:1340-1349.

66. Barsony J, Manigrasso MB, Xu Q, Tam H, Verbalis JG. Chronic hyponatremia exacerbates multiple manifestations of senescence in male rats. Age (Dordr). 2013; 35:271288.

67. Wald R, Jaber BL, Price LL, Upadhyay A, Madias NE. Impact of hospital-associated hyponatremia on selected outcomes. Arch Intern Med. 2010; 170:294-302.

68. Adrogué HJ, Madias NE. Hyponatremia. N Engl J Med. 2000; 342:1581-1589.

69. Goma EM, Vagelos RH, Fowler MB, Ashley EA. Emerging therapies for the management of decompensated heart failure: from bench to bedside. J Am Coll Cardiol. 2006; 48:2397-2409.

70. Der-Nigoghossian C, Lesch C, Berger K. Effectiveness and tolerability of conivaptan and tolvaptan for the treatment of hyponatremia in neurocritically ill patients. Pharmacotherapy. 2017; 37:528-534.

71. Murphy T, Dhar R, Diringer M. Conivaptan bolus dosing for the correction of hyponatremia in the neurointensive care unit. Neurocrit Care. 2009; 11:14-19.

72. Vaz FJ, Salcedo MS. Fluoxetine treatment of depressive symptoms in acute intermittent porphyria. J Clin Psychiatry. 1991; 52:138.

73. Brun A. The drug database for acute porphyria. Nor Porphyria Cent. 2017; http://www drugs-porphyria.org (accessed July 29, 2020).

74. Zhou B, Tishler PV. American Porphyria Foundation Drug Database. http://www. porphyriafoundation.com/ drug-database (accessed July 29, 2020).

75. Frias N. Porphyria drug safety 2016 . http:// porphyriadrugs.com/ (accessed July 29, 2020).

76. Bonkovsky HL, Siao P, Roig Z, Hedley-Whyte ET, Flotte TJ. Case records of the Massachusetts General Hospital. Case 20 - 2008. A 57-year-old woman with abdominal pain and weakness after gastric bypass surgery. N Engl J Med. 2008; 358:2813-2825.

77. Hift RJ, Meissner PN. An analysis of 112 acute porphyric attacks in Cape Town, South Africa: Evidence that acute intermittent porphyria and variegate porphyria differ in susceptibility and severity. Medicine (Baltimore). 2005; 84:48-60.

78. Innala E, Bäckström T, Bixo M, Andersson C. Evaluation of gonadotropin-releasing hormone agonist treatment for prevention of menstrual-related attacks in acute porphyria. Acta Obstet Gynecol Scand. 2010; 89:95-100.

79. Anderson KE, Spitz IM, Bardin CW, Kappas A. A gonadotropin releasing hormone analogue prevents cyclical attacks of porphyria. Arch Intern Med. 1990;
150:1469-1474

80. Herrick AL, McColl KE, Wallace AM, Moore MR, Goldberg A. LHRH analogue treatment for the prevention of premenstrual attacks of acute porphyria. Q J Med. 1990; 75:355-363.

81. Marsden JT, Guppy S, Stein P, Cox TM, Badminton M, Gardiner T, Barth JH, Stewart MF, Rees DC. Audit of the use of regular haem arginate infusions in patients with acute porphyria to prevent recurrent symptoms. JIMD Rep. 2015; 22:57-65.

82. Glueck R, Green D, Cohen I, Ts'ao CH. Hematin: Unique effects of hemostasis. Blood.1983; 61:243-249.

83. Willandt B, Langendonk JG, Biermann K, Meersseman W, D'Heygere F, George C, Verslype C, Monbaliu D, Cassiman D. Liver fibrosis associated with iron accumulation due to long-term heme-arginate treatment in acute intermittent porphyria: A case series. JIMD Rep. 2016; 25:77-81.

84. Yarra P, Faust D, Bennett M, Rudnick S, Bonkovsky HL. Benefits of prophylactic heme therapy in severe acute intermittent porphyria. Mol Genet Metab Rep. 2019; 19:100450.

85. Dowman JK, Gunson BK, Mirza DF, Bramhall SR, Badminton MN, Newsome PN; UK Liver Selection and Allocation Working Party. Liver transplantation for acute intermittent porphyria is complicated by a high rate of hepatic artery thrombosis. Liver Transpl. 2012; 18:195200.

86. Singal AK, Parker C, Bowden C, Thapar M, Liu L, McGuire BM. Liver transplantation in the management of porphyria. Hepatology. 2014; 60:1082-1089.

87. Seth AK, Badminton MN, Mirza D, Russell S, Elias E. Liver transplantation for porphyria: Who, when, and how? Liver Transpl. 2007; 13:1219-1227.

88. Ajayi T, Ward R, Summers B, et al. Pathophysiology, pharmacology and treatment of acute intermittent porphyria: A patient case description and recommendations from the current literature. J Explor Res Pharmacol. 2017; 2:49-53.

89. Nikam RR, Gore KR. Journey of siRNA: Clinical developments and targeted delivery. Nucleic Acid Ther. 2018; 28:209-224.

90. Paula Brandão PR, Titze-de-Almeida SS, Titze-deAlmeida R. Leading RNA interference therapeutics Part 2: Silencing delta-aminolevulinic acid synthase 1 , with a focus on givosiran. Mol Diagn Ther. 2020; 24:61-68.

91. Scott LJ. Givosiran: First approval. Drugs. 2020; 80:335339.

92. Chan A, Liebow A, Yasuda M, et al. Preclinical development of a subcutaneous ALAS1 RNAi therapeutic for treatment of hepatic porphyrias using circulating RNA quantification. Mol Ther Nucleic Acids.2015; 4:e263.

93. Zimmermann TS, Lee AC, Akinc A, et al. RNAimediated gene silencing in non-human primates. Nature. 2006; 441:111-114.

94. Yasuda M, Gan L, Chen B, Kadirvel S, Yu C, Phillips JD, New MI, Liebow A, Fitzgerald K, Querbes W, Desnick RJ. RNAi-mediated silencing of hepatic Alas1 effectively prevents and treats the induced acute attacks in acute intermittent porphyria mice. Proc Natl Acad Sci USA. 2014; 111:7777-7782.

95. Sardh E, Harper P, Balwani M, Stein P, et al. Phase 1 trial of an RNA interference therapy for acute intermittent porphyria. N Eng J Med. 2019; 380:549-558.

96. Agarwal S, Simon AR, Goel V, Habtemariam BA, 
Clausen VA, Kim JB, Robbie GJ. Pharmacokinetics and pharmacodynamics of the small interfering ribonucleic acid, givosiran, in patients with acute hepatic porphyria. Clin Pharmacol Ther. 2020; 108:63-72.

97. Balwani M, Sardh E, Ventura P, et al.; ENVISION Investigators. Phase 3 trial of RNAi therapeutic givosiran for acute intermittent porphyria. N Engl J Med. 2020; 382:2289-2301.

98. Alnylam Pharmaceuticals. Givlaari (Givosiran): US prescribing information. 2019. http://www.accessdata.fda. gov/ (accessed December 2, 2019).

99. LiverTox: Clinical and Research Information on DrugInduced Liver Injury [Internet]. Bethesda (MD): National Institute of Diabetes and Digestive and Kidney Diseases; 2012. http://www.livertox.nih.gov/ (accessed February 27, 2020).

100. Ahmed A, Rahman M, Zhang X, Acevedo CH, Nijjar S, Rushton I, Bussolati B, St John J. Induction of placental heme oxygenase-1 is protective against TNFalpha-induced cytotoxicity and promotes vessel relaxation. Mol Med. 2000; 6:391-409.

101. FDA. FDA approves first treatment for inherited rare disease [media release]. 20 Nov2019. $h t t p: / / w w w . f d a . g o v /$ (accessed December 2, 2019).

102. Fontanellas A, Ávila MA, Anderson KE, Deybach JC. Current and innovative emerging therapies for porphyrias with hepatic involvement. J Hepatol. 2019; 71:422-433.

103. Johansson A, Nowak G, Möller C, Harper P. Non-viral delivery of the porphobilinogen deaminase cDNA into a mouse model of acute intermittent porphyria. Mol Genet Metab. 2004; 82:20-26.

104. Johansson A, Nowak G, Möller C, Blomberg P, Harper P. Adenoviral-mediated expression of porphobilinogen deaminase in liver restores the metabolic defect in a mouse model of acute intermittent porphyria. Mol Ther. 2004; 10:337-43.

105. Brunetti-Pierri N, Newsome PN. AAV-mediated liverdirected gene therapy for acute intermittent porphyria: It is safe but is it effective? J Hepatol. 2016; 65:666-667.

106. Unzu C, Sampedro A, Mauleón I, Alegre M, Beattie SG, de Salamanca RE, Snapper J, Twisk J, Petry H, González AG, Artieda J, Rodríguez PMS, Prieto J, Fontanellas A. Sustained enzymatic correction by rAAV-mediated liver gene therapy protects against induced motor neuropathy in acute porphyria mice. Mol Ther. 2011; 19:243-250.

107. Yasuda M, Bishop DF, Fowkes M, Cheng SH, Gan L, Desnick RJ. AAV8-mediated gene therapy prevents induced biochemical attacks of acute intermittent porphyria and improves neuromotor function. Mol Ther. 2010; 18:17-22.

108. Serrano MI, Sampedro A, Alegre M, Enríquez de Salamanca R, Berraondo P, Fontanellas A. An inducible promoter responsive to different porphyrinogenic stimuli improves gene therapy vectors for acute intermittent porphyria. Hum Gene Ther. 2018; 29:480-491.

109. Serrano MI, Sampedro A, Serna N, de Salamanca
RE, Sanz-Parra A, Corrales F, Berraondo P, Millet O, Fontanellas A. Bioengineered PBGD variant improves the therapeutic index of gene therapy vectors for acute intermittent porphyria. Hum Mol Genet. 2018; 27:36883696.

110. AIP gene Website. https://www.aipgene.org (accessed August 5, 2016).

111. D'Avola D, López-Franco E, Sangro B, et al. Phase I open label liver-directed gene therapy clinical trial for acute intermittent porphyria. J Hepatol. 2016; 65:776-783.

112. Nault JC, Datta S, Imbeaud S, et al. Recurrent AAV2related insertional mutagenesis in human hepatocellular carcinomas. Nat Genet. 2015; 47:1187-1193.

113. Puy H, Deybach JC, Gouya L. Systemic administered mRNA as therapy for metabolic diseases. Trends Mol Med. 2019; 25:3-5.

114. Martini PGV, Guey LT. A new era for rare genetic diseases: Messenger RNA therapy. Hum Gene Ther. 2019; 30:1180-1189.

115. Berraondo P, Martini PGV, Avila MA, Fontanellas A. Messenger RNA therapy for rare genetic metabolic diseases. Gut. 2019; 68:1323-1330.

116. Sabnis S, Kumarasinghe ES, Salerno T, Mihai C, Ketova T, Senn JJ, Lynn A, Bulychev A, McFadyen I, Chan J, Almarsson Ö, Stanton MG, Benenato KE. A novel amino lipid series for mRNA delivery: Improved endosomal escape and sustained pharmacology and safety in nonhuman primates. Mol Ther. 2018; 26:1509-1519.

117. Jiang L, Berraondo P, Jericó D, et al. Systemic messenger RNA as an etiological treatment for acute intermittent porphyria. Nat Med. 2018; 24:1899-1909.

118. Pallet N, Mami I, Schmitt C, Karim Z, François A, Rabant M, Nochy D, Gouya L, Deybach JC, Xu-Dubois Y, Thervet E, Puy H, Karras A. High prevalence of and potential mechanisms for chronic kidney disease in patients with acute intermittent porphyria. Kidney Int. 2015; 88:386-395.

119. Stölzel U, Doss MO, Schuppan D. Clinical guide and update on porphyrias. Gastroenter ology. 2019; 157:365381.e4.

120. Cederlöf M, Bergen SE, Larsson H, Landén M, Lichtenstein P. Acute intermittent porphyria: comorbidity and shared familial risks with schizophrenia and bipolar disorder in Sweden. Br J Psychiatry. 2015; 207:556-557.

Received August 7, 2020; Revised August 20, 2020; Accepted August 23, 2020.

*Address correspondence to:

Songyun Zhang, Department of Endocrinology, The second Hospital of Hebei Medical University, Shijiazhuang 050000, Hebei, China.

E-mail: zsy2020@hebmu.edu.cn

Released online in J-STAGE as advance publication August 24, 2020. 